\title{
O CONTROLE DE CONVENCIONALIDADE NO DIREITO \\ INTERNACIONAL DO TRABALHO COMO INSTRUMENTO DE \\ GARANTIA DO TRABALHO DECENTE NO BRASIL: O Caso dos
}

Trabalhadores da Fazenda Brasil Verde

THE CONVENTIONALITY CONTROL IN INTERNATIONAL LABOR

LAW AS A DECENT WORK GUARANTEE INSTRUMENT IN BRAZIL:

The Case of "Trabalhadores da Fazenda Brasil Verde"

\author{
Mara Vidigal Darcanchy ${ }^{1}$ \\ Patricia Grazziotin Noschang ${ }^{2}$ \\ Sirlene Elias Ribeiro ${ }^{3}$
}

\section{Resumo}

O conceito de trabalho decente, formalizado em 1999 pela Organização Internacional do Trabalho, determina a garantia de um exercício laboral digno, produtivo e de qualidade, respeitando a equidade, a liberdade e a segurança. $\mathrm{O}$ trabalho decente também é considerado condição fundamental para superar a pobreza, reduzir as desigualdades sociais e fomentar a democracia e o desenvolvimento sustentável. Como corolário desse conceito amplo, neste estudo, buscou-se trabalhar com dois elementos específicos: a dignidade da pessoa humana e o desenvolvimento sustentável, diante da compreensão de que a atividade laboral deve respeitar o meio ambiente, associada à garantia de saúde e bem-estar do trabalhador e de todos que habitam este planeta. Com o suporte metodológico da abordagem dedutiva e da pesquisa bibliográfica, a problemática especificamente enfrentada consiste em examinar a garantia do trabalho decente no Brasil, aplicando, para tanto, o controle de convencionalidade no direito internacional do trabalho atrelado às normas de proteção aos direitos humanos, diretamente

\footnotetext{
${ }^{1}$ Pós-Doutora em Direito Internacional (UNIPg/IT); Doutora e Mestre em Direito das Relações Sociais (PUC/SP). Professora Pesquisadora e PNPD-CAPES ${ }^{1}$ do Programa de Doutorado e Mestrado em Direito Empresarial e Cidadania do Centro Universitário Curitiba UNICURITIBA; Membro da Comissão Consultiva da OIT.e Gerente voluntária de Projetos da ONU Mulheres/Meninas. Contato: mdarcanchy@gmail.com

${ }^{2}$ Doutora e Mestre em Direito Internacional pelo PPGD/UFSC,

Professora na Faculdade de Direito e do Programa de Pós-Graduação em Direito (Mestrado) da Universidade de Passo Fundo/RS. Membro do Módulo Jean Monnet CCJ/UFSC. Contato: patriciagn@ upf.br

${ }^{3}$ Mestre em Direito Empresarial e Cidadania pelo Centro Universitário Curitiba UNICURITIBA, Especialista em Direito Civil e Processual Civil e Direito Tributário Contemporâneo - Centro Universitário Curitiba, Advogada coordenadora de setor jurídico empresarial. Coordenadora de pesquisa doutrinária e jurisprudencial na Editora Juruá. Contato: sirlene.elias@ hotmail.com
} 
conectado com os princípios da dignidade da pessoa humana e do desenvolvimento sustentável. Como exemplo fático da relação dignidade da pessoa humana e meio ambiente, utilizou-se o caso dos trabalhadores da Fazenda Brasil Verde, que ocasionou a primeira condenação do Brasil em matéria de trabalho escravo no Sistema Interamericano de Proteção aos Direitos Humanos. "O presente trabalho foi realizado com parcial apoio da Coordenação de Aperfeiçoamento de Pessoal de Nível Superior - Brasil (CAPES) - Código de Financiamento 001" (Portaria n. 206/2018 - CAPES).

Palavras-chave: Controle de convencionalidade. Desenvolvimento sustentável. Dignidade da pessoa. Direito internacional do trabalho. Trabalho decente. Trabalhadores da Fazenda Brasil Verde.

\begin{abstract}
The decent work concept, formalized in 1999 by the International Labour Organization, determines the guarantee of a dignified, productive and quality labor practice, respecting equity, freedom and security. Decent work is also seen as a fundamental condition for overcoming poverty, reducing social inequalities, promoting democracy and sustainable development. As a corollary of this broad concept, in this study, we sought to work with two specific elements: the dignity of the human person and sustainable development in the face of the understanding that work activity must respect the environment, associated with health and well-being the worker and all who inhabit this planet. With the methodological support of the deductive approach and bibliographical research, the specific problem faced is to examine the guarantee of decent work in Brazil applying to it the control of conventionality in international labor law, linked to the norms of human rights protection, directly connected with the principles of human dignity and sustainable development. As a factual example of the relationship between the dignity of the human person and the environment, the case of the employees of Fazenda Brasil Verde was used, which caused Brazil's first condemnation of slave labor in the Inter-American System for the Protection of Human Rights. "This study was financed in part by the Coordenação de Aperfeiçoamento de Pessoal de Nível Superior - Brasil (CAPES) - Finance Code 001" (Ordinance N. 206/2018 - CAPES).
\end{abstract}

Keywords: Conventionality control. Sustainable development. Dignity of the person. International labor law. Decent work. Workers of the Fazenda Brasil Verde.

\title{
INTRODUÇÃO
}

O controle de convencionalidade ocorre quando o Estado signatário realiza a adequação do seu ordenamento jurídico interno às normas/compromissos internacionais (tratados) a que se vinculou.

O termo convencionalidade surgiu na França, em um julgamento do Conselho Constitucional francês em 1975. Na Decisão $\mathrm{n}^{\circ}$ 74-54 DC, o Conselho se declarou incompetente para analisar se uma lei interna era compatível com um tratado, no caso, a Convenção Europeia de Direitos Humanos. Na oportunidade, o Conselho entendeu que sua competência abrangia apenas fazer o controle de constitucionalidade, ou seja, examinar a compatibilidade da lei com 
a Constituição francesa e não um "controle de convencionalidade". A partir desta decisão, o Conselho reconheceu que uma norma interna deve passar por "dois crivos" de compatibilidade para que seja considerada válida e eficaz: a Constituição e os tratados ratificados e em vigor no país (MAZZOULI, 2013, p. 744).

No caso do Sistema Americano de Proteção aos Direitos Humanos, o controle de convencionalidade externo é realizado pela Corte Interamericana de Direitos Humanos, que ao emitir pareceres consultivos e proferir sentenças zela pela aplicação adequada dos tratados de direitos humanos celebrados e em vigor no âmbito regional sob sua guarda e jurisdição (NOSCHANG, 2016, 2017).

O termo controle de convencionalidade surgiu de forma expressa, em 2006, na jurisprudência da Corte Interamericana de Direitos Humanos com o julgamento do Caso Almonacid Arellano e outros v. Chile, ante o entendimento de que os Estados devem fazer a revisão de suas normas internas e amoldar os seus ordenamentos jurídicos à Convenção Americana de Direitos Humanos e à interpretação da Corte Interamericana de Direitos Humanos relativamente aos tratados de direitos humanos.

As condenações contra o Estado brasileiro no Sistema Interamericano de Direitos Humanos, que referem à ausência do exercício interno do controle de convencionalidade de forma expressa, iniciaram em 2010 com o caso Gomes Lund e outros v. Brasil e seguem nas demais sentenças como: Trabalhadores da Fazenda Brasil Verde v. Brasil; Favela Nova Brasília v. Brasil; Povo Indígena do Xucuru v. Brasil e Herzog e outros v. Brasil.

De todos os casos que o Brasil foi condenado na Corte Interamericana de Direitos Humanos, o caso dos trabalhadores da Fazenda Brasil Verde é o primeiro (e único até o momento) que aborda a condição de trabalho escravo no país. Sabe-se que esta prática é comum nos latifúndios localizados nas regiões Norte e Centro-Oeste do país. Esta sentença, a propósito, destaca a ausência do controle de convencionalidade no Brasil em matéria de direito internacional do trabalho averiguando o descumprimento da Convenção Americana de Direitos Humanos e das convenções da Organização Internacional do Trabalho.

Assim, com uma abordagem apoiada no método dedutivo e na técnica de pesquisa bibliográfica, este artigo busca, primeiramente, apresentar o conceito de trabalho decente, destacando primeiramente dois elementos importantes para análise do caso dos trabalhadores da Fazenda Brasil Verde: a dignidade da pessoa humana e o desenvolvimento sustentável, para, em seguida, analisar a sentença da Corte Interamericana de Direitos Humanos que demonstra a ausência do controle de convencionalidade em matéria de direito internacional do trabalho no Brasil. 


\section{CONCEITO DE TRABALHO DECENTE: DIGNIDADE DA PESSOA HUMANA PLUS DESENVOLVIMENTO SUSTENTÁVEL}

A Organização Internacional do Trabalho (OIT) foi fundada em 1919 pelo Tratado de Versalhes, no período pós-Primeira Guerra Mundial, com o objetivo de promover a justiça social. A OIT é a única organização internacional com estrutura tripartite composta por representantes dos Estados (183 Estados-membros), representantes dos empregadores e representantes dos empregados (ORGANIZAÇÃO INTERNACIONAL DO TRABALHO, Conheça a OIT, [s.d.]). Atualmente, a missão dessa organização é a garantia de um trabalho decente para homens e mulheres, em condições de igualdade, dignidade, liberdade e segurança.

A dignidade do trabalhador é tema de um dos principais documentos da OIT: a Declaração de Filadélfia de 1944, que com a Carta de Constituição passou a ser o documento que propõe os objetivos e os princípios da referida organização.

A Declaração da Filadélfia reafirmou que a paz para ser duradoura deve fundamentarse na justiça social, garantindo-se que todos os seres humanos: “[...] de qualquer raça, crença ou sexo, têm o direito de assegurar o bem-estar material e o desenvolvimento espiritual dentro da liberdade e da dignidade, da tranqüilidade econômica e com as mesmas possibilidades; [...]". Para que esses direitos sejam garantidos, os Estados devem promover "[...] a realização de condições que permitam o exercício de tal direito deve constituir o principal objetivo de qualquer política nacional ou internacional; [...]” (ORGANIZAÇÃO INTERNACIONAL DO TRABALHO, Constituição da OIT (1944) e Declaração da Filadélfia (1946), [s.d.]).

Em 1998, a Declaração da OIT relativa a princípios e direitos fundamentais no trabalho reafirmou o compromisso dos membros da organização de respeitarem e promoverem os direitos de trabalhadores e de empregadores, a liberdade sindical, a liberdade de negociação coletiva, bem como trabalharem para eliminar todas as formas de trabalho forçado ${ }^{4}$, discriminação no emprego ou ocupação e trabalho infantil. A Declaração reconhece como princípios fundamentais da OIT, sete convenções quais sejam: 87 sobre liberdade sindical e proteção aos direitos sindicais; 98 sobre a liberdade de sindicalização e de negociação coletiva;

\footnotetext{
${ }^{4}$ De acordo com a Convenção n. 29 da OIT (adotada em 1930), trabalho forçado ou compulsório é todo trabalho ou serviço exigido de uma pessoa sob ameaça de uma sanção e para o qual a pessoa não se ofereceu espontaneamente. Sua exploração pode ser feita por autoridades do Estado, pela economia privada ou por pessoas físicas. O conceito é amplo e, portanto, abrange um vasto leque de práticas coercitivas de trabalho que ocorrem em todos os tipos de atividades econômicas e em todas as partes do mundo (ORGANIZAÇÃO INTERNACIONAL DO TRABALHO, O que é trabalho forçado? [s.d.]).
} 
29 e 105 sobre a abolição do trabalho forçado; 100 sobre salário igual para trabalho igual entre homem e mulher; 111 sobre a não discriminação no emprego ou ocupação, e 138 sobre idade mínima para o trabalho (SUSSEKIND, 2008, p. 624-625).

$\mathrm{Na}$ evolução do conceito de trabalho digno está a proposta de trabalho decente formulada pela OIT. O trabalho decente passa não só a incluir a dignidade do trabalhador, mas também outros fatores como equidade, liberdade, saúde, redução das desigualdades sociais, erradicação da pobreza e desenvolvimento sustentável.

O conceito de trabalho decente foi proposto em 1999 pela OIT, com o objetivo de garantir um trabalho produtivo e de qualidade para homens e mulheres. A organização intenta promover o trabalho decente como condição principal para a erradicação da pobreza e a diminuição das desigualdades sociais nos seus Estados-membros. Assim, o trabalho decente deve ser realizado "[...] em condições de liberdade, equidade, segurança e dignidade humanas, sendo considerado condição fundamental para a superação da pobreza, a redução das desigualdades sociais, a garantia da governabilidade democrática e o desenvolvimento sustentável” (ORGANIZAÇÃO INTERNACIONAL DO TRABALHO, Trabalho decente, [s.d.]).

A noção de trabalho decente se apóia em quatro pilares estratégicos: “a) o respeito às normas internacionais de proteção ao trabalho; b) a promoção do emprego de qualidade; c) a extensão da proteção social; e d) o diálogo social" (ORGANIZAÇÃO INTERNACIONAL DO TRABALHO, Trabalho decente, [s.d.]).

Do amplo conceito de trabalho decente importam para a presente análise duas premissas: da dignidade da pessoa humana e do desenvolvimento sustentável. A dignidade da pessoa humana porque está atrelada aos direitos fundamentais garantidos internamente pelo ordenamento jurídico dos Estados-membros, seja por norma constitucional, seja por tratado ratificado. O desenvolvimento sustentável por garantir a dignidade do trabalhador em um ambiente saudável e por preservar a natureza.

A dignidade da pessoa humana é assim definida por Sarlet (2001, p. 60):

Qualidade intrínseca e distintiva de cada ser humano que o faz merecedor do mesmo
respeito e consideração por parte do Estado e da comunidade, implicando, neste
sentido, um complexo de direitos e deveres fundamentais que assegurem a pessoa
tanto contra todo e qualquer ato de cunho degradante e desumano, como venham a
lhe garantir as condições existenciais mínimas para uma vida saudável, além de
propiciar e promover sua participação ativa e co-responsável nos destinos da própria
existência e da vida em comunhão com os demais seres humanos.

Para Flávia Piovesan (2009, p. 108), “o ser humano é um ser essencialmente moral, dotado de unicidade existencial e dignidade como um valor intrínseco à condição humana". E 
completa afirmando que “[...] o valor da dignidade humana é um valor intrínseco à condição humana e não um valor extrínseco, a depender da minha condição social, econômica, religiosa, nacional ou qualquer outro critério" (PIOVESAN, 2009, p.108).

A dignidade está prevista e garantida em diplomas legais nacionais e internacionais. Em âmbito interno, está prevista na Constituição Federal em vigor, no artigo $1^{\circ}$, onde apregoa os fundamentos do Estado Democrático de Direito e, entre eles, desponta a dignidade da pessoa humana. ${ }^{5}$

No plano internacional, a dignidade da pessoa humana aparece respaldada em tratados das esferas regional e universal.

A Convenção Americana de Direitos Humanos (Pacto de São José da Costa Rica), de 22 de novembro de 1969, prevê a dignidade no seu artigo $5^{\circ 6}$, que dispõe sobre o direito à integridade pessoal, garantindo o direito de respeito às integridades física, psíquica e moral.

Na esfera universal, a dignidade da pessoa humana é princípio basilar da Declaração Universal de Direitos Humanos de 1948, primeiro diploma legal de proteção dos direitos humanos, no período pós-Segunda Guerra Mundial. Logo no Preâmbulo a Declaração traz a seguinte previsão: “Considerando que o reconhecimento da dignidade inerente a todos os membros da família humana e de seus direitos iguais e inalienáveis é o fundamento da liberdade, da justiça e da paz no mundo, [...]”. A dignidade da pessoa humana também é referida no quinto "Considerando", referindo-se aos princípios previstos na Carta das Nações Unidas de 1945 (UNITED NATIONS, Declaração Universal dos Direitos Humanos, 1948).

No ato constitutivo da Organização das Nações Unidas (ONU) consta a fé nos direitos fundamentais, na dignidade e valor da pessoa humana, bem como na igualdade de direitos entre homens e mulheres. Posteriormente, o artigo $1^{\circ}$ da Declaração de 1948 dispõe que: "Todos os seres humanos nascem livres e iguais em dignidade e em direitos. Dotados de razão e de consciência, devem agir uns para com os outros em espírito de fraternidade." (UNITED NATIONS, Declaração Universal dos Direitos Humanos, 1948).

Para consolidar os princípios contidos na Declaração Universal de Direitos Humanos, dois tratados no âmbito das ONU foram aprovados em 1966: o Pacto Internacional de Direito

\footnotetext{
5 “Art. $1^{\circ}$. A República Federativa do Brasil, formada pela união indissolúvel dos Estados e Municípios e do Distrito Federal, constitui-se em Estado democrático de direito e tem como fundamentos: [...] III - a dignidade da pessoa humana; [...]." (BRASIL, Constituição, 1988).

6 “Artigo $5^{\circ}$. Direito à integridade da pessoa. 1 Toda pessoa tem o direito de que se respeite sua integridade física, psíquica e moral. 2. Ninguém deve ser submetido a torturas, nem a penas ou tratos cruéis, desumanos ou degradantes. Toda pessoa privada da liberdade deve ser tratada com o respeito devido à dignidade inerente ao ser humano." (COMISSÃO INTERAMERICANA DE DIREITOS HUMANOS, Convenção Americana de Direitos Humanos, 1969).
} 
Civis e Políticos e o Pacto Internacional de Direitos Econômicos Sociais e Culturais, valendo salientar que ambos os tratados repetem em seus preâmbulos o previsto na Declaração de 1948 da $\mathrm{ONU}$, em relação à dignidade da pessoa humana, reconhecendo os direitos inerentes a esta condição.

A dignidade humana também é considerada no ambiente de trabalho. A saúde do trabalhador depende de um ambiente que respeite a natureza e com ela se harmonize. Dessa assertiva, extrai-se que o trabalho decente engloba a dignidade da pessoa humana e o desenvolvimento sustentável.

A propósito, a expressão “desenvolvimento sustentável” foi instituída para resumir uma gama de preocupações que podem ser resumidas em três conceitos globais: bem-estar social, economia e meio ambiente. Esses três conceitos desafiam a elaboração de políticas ambientais condizentes com o tripé ou facetas dos desenvolvimentos econômico, social e sustentável, sem o qual não há como garantir um meio ambiente saudável para as presentes e as futuras gerações (WINTER, 2009, p. 1-23) ${ }^{7}$.

Segundo Philippe Sands (2003, p. 252-253), o desenvolvimento sustentável possui quatro elementos no seu conceito jurídico, conforme previstos nos tratados internacionais: o primeiro alude à necessidade de preservar o meio ambiente para futuras gerações; o segundo refere à exploração de recursos naturais de forma prudente, consciente e apropriada; o terceiro prevê o uso equitable dos recursos naturais (os Estados devem levar em consideração as necessidades de seus pares); o quarto elemento tange a necessidade de garantir a proteção ao meio ambiente nos planos de desenvolvimento econômico. Esses quatro elementos estão também vinculados aos princípios do meio ambiente: o primeiro se conecta ao princípio intergeracional equity, o segundo ao princípio do uso sustentável, o terceiro ao princípio do uso adequado ou intergeracional equity e o quarto elemento ao princípio da integração. ${ }^{8}$

A ideia de desenvolvimento sustentável começou a ser desenvolvida em 1980, com a Comissão Mundial para o Meio Ambiente e Desenvolvimento, denominada "Comissão Brundtland”. Esta comissão criou um grupo de especialistas em direito ambiental internacional com o objetivo de elaborar princípios que deveriam ser implementados antes do ano 2000 e que

\footnotetext{
${ }^{7}$ Gerd Winter (2009, p. 1-23) realizou estudo aprofundado sobre os vinte anos da Comissão Mundial do Meio Ambiente e Desenvolvimento (Comissão Brundtland), resultando no relatório intitulado "Nosso Futuro Comum", O relatório teve como objeto principal o "desenvolvimento sustentável", definido como "[...]uso de recursos naturais de forma 'que atenda às necessidades presentes, sem comprometer a capacidade das futuras gerações de suprirem suas próprias necessidades' (Relatório, 2.1)”.

${ }^{8}$ Na mesma concepção de Philippe Sands (2003), ver também Patricia Birnie e Alan Boyle (2009, p. 115-127).
} 
servissem de alicerce para o desenvolvimento sustentável. O relatório da comissão foi adotado em 1987 como uma guideline (SCHRIJVER, 1997, p. 133).

Em 1992, na cidade do Rio de Janeiro, a ONU retomou o debate sobre o meio ambiente para definir novos princípios e novas diretrizes para a preservação do planeta. Nesse encontro, aprovou-se a Declaração do Rio sobre Meio Ambiente e Desenvolvimento, que no seu preâmbulo consigna o objetivo de formar um grupo de ação para agir globalmente tendo em vista "o estabelecimento de novos níveis de cooperação entre os Estados, os setores-chave da sociedade e os indivíduos, trabalhando com vistas à conclusão de acordos internacionais do sistema global de meio ambiente e desenvolvimento [...]" (ORGANIZAÇÃO DAS NAÇÕES UNIDAS, Declaração do Rio sobre Meio Ambiente e Desenvolvimento, 1992). Na parte dispositiva, a Declaração do Rio cataloga vinte e sete princípios para a preservação do meio ambiente.

Nessa esteira, estabeleceram-se novos conceitos, principalmente o de desenvolvimento sustentável, valendo destacar, nos termos da Declaração em comento:

\footnotetext{
Princípio 1 - Os seres humanos estão no centro das preocupações com o desenvolvimento sustentável. Têm direito a uma vida saudável e produtiva, em harmonia com a natureza; [...].

Princípio 3 - $\mathrm{O}$ direito ao desenvolvimento deve ser exercido de modo a permitir que sejam atendidas eqüitativamente as necessidades de gerações presentes e futuras (ORGANIZAÇÃO DAS NAÇÕES UNIDAS, Declaração do Rio sobre Meio Ambiente e Desenvolvimento, 1992).
}

Além desses princípios, a erradicação da pobreza também foi considerada pelos participantes do encontro um quesito indispensável para o desenvolvimento sustentável. O desenvolvimento sustentável, frise-se, objetiva garantir um meio ambiente saudável para a atual e para as próximas gerações, assentada a ideia de que o desenvolvimento econômico deve observar a preservação da natureza como condição de vida humana na Terra.

O trabalho decente inscreve-se entre os objetivos de desenvolvimento sustentável previstos na Agenda 2030 da ONU, de 2015. Ao todo, são dezessete objetivos que buscam concretizar os direitos humanos e alcançar a igualdade de gênero. Acrescente-se que esses objetivos são integrados, indivisíveis e equilibram as três dimensões do desenvolvimento sustentável: econômica, social e ambiental (ORGANIZAÇÃO DAS NAÇÕES UNIDAS, Agenda 2030, 2015). 
Na Agenda 2030, o Objetivo 8 se refere à promoção do crescimento econômico sustentado, inclusivo e sustentável, emprego pleno e produtivo, e trabalho decente para todos. Este objetivo está especificado em mais de dez ações a serem alcançadas até $2030^{9}$.

Percebe-se que o trabalho decente, além de garantir a proteção à dignidade do trabalhador, também está atrelado à questão do desenvolvimento sustentável. Justamente por isso, este estudo busca demonstrar a relação estreita entre dignidade e desenvolvimento sustentável ao abordar o caso da Fazenda Brasil Verde.

O caso que será objeto de análise, logo a seguir, trata da condenação do Estado brasileiro na Corte Interamericana de Direitos Humanos por violação do artigo $6^{\circ}$ da Convenção Americana de Direitos Humanos, que proíbe o trabalho escravo. Além da violação da dignidade desses trabalhadores, principalmente em relação a sua saúde, está outra ação que fere o conceito de trabalho decente: o desmatamento de áreas florestais objetivando utilizar as terras para a pecuária. Esse caso demonstra a relação do trabalho decente: respeito à dignidade dos trabalhadores e desenvolvimento sustentável.

\section{CONTROLE DE CONVENCIONALIDADE DAS NORMAS DA ORGANIZAÇÃO INTERNACIONAL DO TRABALHO E DA CONVENÇÃO AMERICANA DE DIREITOS HUMANOS: A PROTEÇÃO DO TRABALHADOR COMO DIREITO HUMANO NO CASO DA FAZENDA BRASIL VERDE}

O trabalho escravo está positivado em âmbito internacional, nas convenções da $\mathrm{OIT}^{10}$, em âmbito regional na Convenção Americana de Direitos Humanos ${ }^{11}$. No ordenamento jurídico

\footnotetext{
9 “Objetivo 8.5. [...] emprego pleno e produtivo e trabalho decente para todas as mulheres e homens, inclusive para os jovens e as pessoas com deficiência, e remuneração igual para trabalho de igual valor”. "Objetivo 8.4. Melhorar progressivamente, até 2030, a eficiência dos recursos globais no consumo e na produção, e empenhar-se para dissociar o crescimento econômico da degradação ambiental, de acordo com o Plano Decenal de Programas sobre Produção e Consumo Sustentáveis, com os países desenvolvidos assumindo a liderança". "Objetivo 8.7 Tomar medidas imediatas e eficazes para erradicar o trabalho forçado, acabar com a escravidão moderna e o tráfico de pessoas, e assegurar a proibição e eliminação das piores formas de trabalho infantil, incluindo recrutamento e utilização de crianças-soldado, e até 2025 acabar com o trabalho infantil em todas as suas formas." (ORGANIZAÇÃO DAS NAÇÕES UNIDAS NO BRASIL. Agenda 2030, 2015).

${ }^{10}$ Convenção sobre Trabalho Forçado n. 29, de 1930, Convenção sobre a Abolição do Trabalho Forçado n. 105, de 1957 e Protocolo à Convenção sobre Trabalho Forçado, de 2014 (Organização Internacional do Trabalho. Normas Internacionais sobre Trabalho Forçado, 1930).

11 “Artigo 6. Proibição da escravidão e da servidão. 1. Ninguém pode ser submetido à escravidão ou servidão, e tanto estas como o tráfico de escravos e o tráfico de mulheres são proibidos em todas as suas formas. 2 . Ninguém deve ser constrangido a executar trabalho forçado ou obrigatório. Nos países em que se prescreve para certos delitos pena privativa de liberdade acompanhada de trabalhos forçados, esta disposição não pode ser interpretada no sentido de que proíbe o cumprimento da dita pena, imposta por juiz ou tribunal competente. O trabalho forçado
} 
interno, encontra-se disposição a respeito no Código Penal ${ }^{12}$ e na Constituição Federal de 1988 ${ }^{13}$. Contudo, apenas em 1995 o Estado brasileiro começou a reconhecer oficialmente a existência de trabalho escravo no país. "De acordo com a OIT, em 2010 existiam no mundo 12,3 milhões de pessoas submetidas a trabalho forçado, 25.000 das quais estariam no Brasil." (ORGANIZAÇÃO INTERNACIONAL DO TRABALHO, Combatendo o trabalho escravo contemporâneo: o exemplo do Brasil, 2010, p. 56; CORTE INTERAMERICANA DE DERECHOS HUMANOS, Caso Trabajadores de la Hacienda Brasil Verde vs. Brasil Sentencia de 22 de agosto de 2017, p. 27-28).

O poder público, mediante criação de comissões especializadas e de publicações de leis e decretos, iniciou uma série de medidas para combater o trabalho escravo no Brasil. Entre essas medidas está a alteração da redação do artigo 149 do Código Penal, em 2003, e as Portarias n. 540/2004 e n. 2/2011, instituindo o Registro de Empregadores Infratores (a chamada "lista suja”) para consulta por parte de instituições financeiras em casos de pedidos de créditos.

Contudo, essas e outras ações realizadas pelo Estado brasileiro não foram suficientes para evitar a condenação do Brasil na Corte Interamericana de Direitos Humanos no caso concernente aos trabalhadores da Fazenda Brasil Verde.

\footnotetext{
não deve afetar a dignidade nem a capacidade física e intelectual do recluso. 3. Não constituem trabalhos forçados ou obrigatórios para os efeitos deste artigo: a) os trabalhos ou serviços normalmente exigidos de pessoa reclusa em cumprimento de sentença ou resolução formal expedida pela autoridade judiciária competente. Tais trabalhos ou serviços devem ser executados sob a vigilância e controle das autoridades públicas, e os indivíduos que os executarem não devem ser postos à disposição de particulares, companhias ou pessoas jurídicas de caráter privado; b) o serviço militar e, nos países onde se admite a isenção por motivos de consciência, o serviço nacional que a lei estabelecer em lugar daquele; c) o serviço imposto em casos de perigo ou calamidade que ameace a existência ou o bem-estar da comunidade; e d) o trabalho ou serviço que faça parte das obrigações cívicas normais." (COMISSÃO INTERAMERICANA DE DIREITOS HUMANOS. Convenção Americana de Direitos Humanos, 1969).

${ }^{12}$ Redução à condição análoga à de escravo. "Art. 149. Reduzir alguém a condição análoga à de escravo, quer submetendo-o a trabalhos forçados ou a jornada exaustiva, quer sujeitando-o a condições degradantes de trabalho, quer restringindo, por qualquer meio, sua locomoção em razão de dívida contraída com o empregador ou preposto: Pena - reclusão, de dois a oito anos, e multa, além da pena correspondente à violência. $\S 1^{\circ}$ Nas mesmas penas incorre quem: I - cerceia o uso de qualquer meio de transporte por parte do trabalhador, com o fim de retê-lo no local de trabalho; II - mantém vigilância ostensiva no local de trabalho ou se apodera de documentos ou objetos pessoais do trabalhador, com o fim de retê-lo no local de trabalho. § $2^{\circ}$ A pena é aumentada de metade, se o crime é cometido: I - contra criança ou adolescente; II - por motivo de preconceito de raça, cor, etnia, religião ou origem." (BRASIL. Decreto-lei n. 2.848, de 7 de dezembro de 1940. Código Penal).

13 “Art. 243. As propriedades rurais e urbanas de qualquer região do País onde forem localizadas culturas ilegais de plantas psicotrópicas ou a exploração de trabalho escravo na forma da lei serão expropriadas e destinadas à reforma agrária e a programas de habitação popular, sem qualquer indenização ao proprietário e sem prejuízo de outras sanções previstas em lei, observado, no que couber, o disposto no art. $5^{\circ}$. Parágrafo único. Todo e qualquer bem de valor econômico apreendido em decorrência do tráfico ilícito de entorpecentes e drogas afins e da exploração de trabalho escravo será confiscado e reverterá a fundo especial com destinação específica, na forma da lei (Redação dada pela Emenda Constitucional no 81, de 2014).” (BRASIL, Constituição, 1988).
} 
A Fazenda Brasil Verde, localizada no município de Sapucaia, no Sul do estado do Pará, possui uma área total de 1.780 alqueires (8.544 hectares) e tem como principal atividade a pecuária. Na época dos fatos, o proprietário da fazenda era João Luis Quagliato Neto.

As denúncias da prática de trabalho escravo na Fazendo Brasil Verde iniciaram em 1988 e 1989, devido ao desaparecimento de dois trabalhadores adolescentes: Iron Canuto da Silva, de 17 anos, e Luis Ferreira da Cruz, de 16 anos. ${ }^{14}$ Uma das principais atividades realizadas pelos trabalhadores era desmatar áreas para possibilitar a criação de gado. Essa é uma das principais atividades que alicia trabalhadores e os coloca na condição análoga de escravos (CORTE INTERAMERICANA DE DERECHOS HUMANOS, Caso Trabajadores de la Hacienda Brasil Verde vs. Brasil Sentencia de 22 de agosto de 2017, p. 29, nota 83).

Em 12 de novembro de 1998, o Brasil foi denunciado à Comissão Interamericana de Direitos Humanos, em virtude da sua omissão em relação às péssimas condições, análogas às de escravos, em que se encontravam trabalhadores na Fazenda Brasil Verde. O Relatório de Admissibilidade e Mérito, emitido em 3 de novembro de 2011, determinou uma série de recomendações ao Estado brasileiro, que não foram cumpridas. Em 4 de março de 2015, a Comissão levou o caso à Corte Interamericana de Direitos Humanos. A sentença proferida em 20 de outubro de 2016 declarou, por unanimidade, que o Brasil foi responsável pela violação do direito a não ser submetido à escravidão e ao tráfico de pessoas, estabelecido no artigo 6.1 da Convenção Americana de Direitos Humanos e em relação aos artigos 1.1, 3, 5, 7, 11, 22 do mesmo instrumento, em prejuízo dos oitenta e cinco trabalhadores resgatados em 15 de março de 2000 na Fazenda Brasil Verde. Também por unanimidade, foi considerado responsável por violar as garantias judiciais de devida diligência e de prazo razoável previstas no artigo 8.1 da Convenção Americana sobre Direitos Humanos e em relação ao artigo 1.1 do mesmo instrumento, em prejuízo dos quarenta e três trabalhadores da Fazenda Brasil Verde encontrados durante a fiscalização de 23 de abril de 1997. E, por cinco votos a favor e um contra, ficou consignado que o Brasil violou o direito à proteção judicial prevista no artigo 25 do mesmo diploma em relação aos quarenta e três trabalhadores encontrados na referida fazenda em 1997 e aos oitenta e cinco trabalhadores encontrados em 2000 (CORTE INTERAMERICANA DE DERECHOS HUMANOS, Caso Trabajadores de la Hacienda Brasil Verde vs. Brasil Sentencia de 22 de agosto de 2017, p. 4, 123).

\footnotetext{
${ }^{14}$ Iron Canuto morreu assassinado em 22 de dezembro de 2007 em circunstâncias que não estão relacionadas ao caso. Luis Ferreira da Cruz morreu em 2005 e teria sido enterrado como indigente por não ter nenhum documento de identificação. A Corte entendeu que as informações referentes a Luis Ferreira da Cruz eram controversas (CORTE INTERAMERICANA DE DERECHOS HUMANOS, 2017, p. 108).
} 
A decisão da Corte Interamericana de Direitos Humanos, no caso dos trabalhadores da Fazenda Brasil Verde, protagonizou a primeira condenação do Brasil em âmbito internacional, em relação ao trabalho escravo.

Quanto ao conceito de trabalho escravo, servidão e escravidão, a Corte realizou um estudo do termo escravidão em tratados e documentos internacionais e também na jurisprudência de Tribunais Internacionais que abordaram a temática, como: Tribunal Penal $A d$ Hoc para antiga Iugoslávia, Tribunal Especial para Serra Leoa, Corte Europeia de Direitos Humanos, Corte Internacional de Justiça e Corte de Justiça da Comunidade Econômica da África Ocidental.

A Corte considerou que, atualmente, para se considerar uma situação de escravidão, os seguintes elementos, que são "atributos do direito de propriedade", devem ser observados:
a) restrição ou controle da autonomia individual;
b) perda ou restrição da liberdade de movimento de uma pessoa;
c) obtenção de um benefício por parte do perpetrador;
d) ausência de consentimento ou de livre arbítrio da vítima, ou sua impossibilidade ou irrelevância devido à ameaça de uso da violência ou outras formas de coerção, o medo de violência, fraude ou falsas promessas;
e) uso de violência física ou psicológica;
f) posição de vulnerabilidade da vítima;
g) detenção ou cativeiro;
i) exploração (CORTE INTERAMERICANA DE DERECHOS HUMANOS, Caso
Trabajadores de la Hacienda Brasil Verde vs. Brasil Sentencia de 22 de agosto de 2017, p. 72).

Em relação ao trabalho forçado, a Corte considerou a definição apresentada pelo artigo 2.1 da Convenção n. 29 da OIT, segundo a qual: "[a] expressão 'trabalho forçado ou obrigatório' designará todo trabalho ou serviço exigido de um indivíduo sob ameaça de qualquer penalidade e para o qual ele não se ofereceu de espontânea vontade" (CORTE INTERAMERICANA DE DERECHOS HUMANOS, Caso Trabajadores de la Hacienda Brasil Verde vs. Brasil Sentencia de 22 de agosto de 2017, p. 77).

Neste ponto, é importante destacar que não é objetivo deste estudo analisar o conceito de escravidão e/ou trabalho forçado, mas apenas examinar como a Corte trabalhou e aplicou estes conceitos, que não são considerados sinônimos, mas se inter-relacionam.

A sentença determinou, então, que o Brasil deve exercer o controle de convencionalidade interno, aplicando as normas internacionais a que está vinculado. Esse controle de convencionalidade, ressalte-se, deve ser realizado pelo Estado brasileiro toda vez que assina ou adere a um tratado, realizando as adequações necessárias no seu ordenamento jurídico interno para que a norma internacional passe a ser efetiva, sem entraves ou confrontos 
com o direito interno. Esta determinação está prevista no artigo $2^{\circ}$ da Convenção Americana de Direitos Humanos e no artigo 19 da Constituição da OIT.

No caso em análise, o controle de convencionalidade deveria ter ocorrido em relação à Convenção Americana de Direitos Humanos e às normas de direito internacional do trabalho oriundas da OIT.

Em relação à Convenção Americana de Direitos Humanos, a Corte afirma que o Estado brasileiro deveria ter tomado medidas efetivas de direito interno - o chamado effet utile (CORTE INTERAMERICANA DE DERECHOS HUMANOS, Caso Trabajadores de la Hacienda Brasil Verde vs. Brasil Sentencia de 22 de agosto de 2017, p. 103).

A OIT, por sua vez, na sua Declaração de Princípios e Direitos Fundamentais do Trabalho ${ }^{15}$ determina que mesmo que os Estados não tenham ratificado as convenções, pelos simples fato de serem partes da Organização, devem respeitar, promover e realizar de boa-fé os princípios que fazem parte da Constituição da OIT. Entre esses princípios está a eliminação de todas as formas de trabalho forçado ou obrigatório.

Como se vê, as normas de proteção do trabalhador advindas do plano internacional são também normas de proteção dos direitos humanos e de caráter fundamental, a exemplo do conceito de trabalho decente que inclui a dignidade da pessoa humana. Desta forma, como foram recepcionadas pelo ordenamento jurídico brasileiro antes da Emenda Constitucional $\mathrm{n}$. 45/2004 e, considerando a jurisprudência do Supremo Tribunal Federal (STF), devem ser consideradas supralegais. Por essa razão, prevalecem sobre as demais normativas internas, cabendo ao Estado brasileiro, com os seus três poderes, exercer o controle de convencionalidade nas esferas administrativas, legislativas e judiciais.

Além do status da norma internacional no ordenamento jurídico interno, também é importante ressaltar que na hipótese de as normas de direito internacional do trabalho entrarem

\footnotetext{
${ }^{15}$ Declaração da OIT relativa a Princípios e Direitos Fundamentais no Trabalho. “A Conferência Internacional do Trabalho. 1. Recorda: a) Que ao aderir livremente à OIT, todos os seus Membros aceitaram os princípios e direitos enunciados na sua Constituição e na Declaração de Filadélfia, e comprometeram-se a trabalhar na realização dos objetivos gerais da Organização, em toda a medida das suas possibilidades e da sua especificidade; b) Que esses princípios e direitos foram formulados e desenvolvidos sob a forma de direitos e de obrigações específicos nas convenções que são reconhecidas como fundamentais dentro e fora da Organização. 2. Declara que todos os Membros, mesmo que não tenham ratificado as convenções em questão, têm o dever, que resulta simplesmente de pertencerem à Organização, de respeitar, promover e realizar, de boa fé e de acordo com a Constituição, os princípios relativos aos direitos fundamentais que são objeto dessas convenções, a saber: a) A liberdade de associação e o reconhecimento efetivo do direito de negociação coletiva; b) A eliminação de todas as formas de trabalho forçado ou obrigatório; c) A abolição efetiva do trabalho infantil; d) A eliminação da discriminação em matéria de emprego e de profissão." (ORGANIZAÇÃO INTERNACIONAL DO TRABALHO, Declaração da OIT relativa a Princípios e Direitos Fundamentais no Trabalho, 1998).
} 
em conflito com o direito interno, tomará peso o princípio pro persona. É o que determina o artigo 19, parágrafo 8, da Constituição da OIT:

8. Em caso algum, a adopção de uma convenção ou de uma recomendação pela Conferência, ou a ratificação de uma convenção por um Membro devem ser consideradas como podendo afectar qualquer lei, qualquer sentença, qualquer costume ou qualquer acordo que assegurem condições mais favoráveis para os trabalhadores interessados que as previstas pela convenção ou recomendação (ORGANIZAÇÃO INTERNACIONAL DO TRABALHO, Documentos Fundamentais da OIT, 2007, p. 15).

Somado ao retrocitado dispositivo da Constituição da OIT está o artigo 29 da Convenção Americana de Direitos Humanos, que dispõe que as normas devem ser sempre interpretadas in bonam partem $^{16}$.

Portanto, o entendimento que exsurge é que prevalece a aplicação do princípio da norma mais benéfica ao trabalhador, considerando, como regra, a sua condição de hipossuficiente.

\footnotetext{
16 “Artigo 29. Normas de interpretação. Nenhuma disposição desta Convenção pode ser interpretada no sentido de: a. permitir a qualquer dos Estados Partes, grupo ou pessoa, suprimir o gozo e exercício dos direitos e liberdades reconhecidos na Convenção ou limitá-los em maior medida do que a nela prevista; b. limitar o gozo e exercício de qualquer direito ou liberdade que possam ser reconhecidos de acordo com as leis de qualquer dos Estados Partes ou de acordo com outra convenção em que seja parte um dos referidos Estados; c. excluir outros direitos e garantias que são inerentes ao ser humano ou que decorrem da forma democrática representativa de governo; e d. excluir ou limitar o efeito que possam produzir a Declaração Americana dos Direitos e Deveres do Homem e outros atos internacionais da mesma natureza." COMISSÃO INTERAMERICANA DE DIREITOS HUMANOS. Convenção Americana de Direitos Humanos, 1969).
} 


\section{CONCLUSÃO}

O caso dos trabalhadores da Fazenda Brasil Verde demonstra que no Brasil ainda há muito que fazer para a erradicação do trabalho escravo. Demonstra também que todas as ações tomadas pelo Estado brasileiro em relação à prática do trabalho escravo não foram suficientes. Acredita-se que um dos motivos é a ausência de responsabilidade penal dos autores desta prática ilícita.

Além da falta de punibilidade, há a omissão do Brasil em realizar um controle de convencionalidade, seja de forma difusa, pelos juízos de primeiro grau e pelos tribunais de segunda instância, seja de forma concentrada, pelas altas cortes brasileiras.

Se a aplicação da Convenção Americana de Direitos Humanos e as Convenções da OIT fossem respeitadas nos juízos de primeiro grau, ao exercer o controle de convencionalidade talvez fosse possível garantir a dignidade desses trabalhadores e coibir a prática do trabalho escravo. Contudo, algumas regiões do Brasil ainda sofrem com a influência político-econômica dos grandes latifundiários que determinam as "regras do jogo".

O caso analisado demonstrou também como relacionar dois conceitos incluídos na definição maior de trabalho decente, bandeira da OIT. Somam-se ao caso dos trabalhadores da Fazenda Brasil Verde os conceitos de desenvolvimento sustentável e de dignidade da pessoa humana. Na verdade, percebe-se o desrespeito à dignidade humana ao permitir que pessoas trabalhem em condições análogas às de escravos e também no que tange ao desenvolvimento sustentável quando, sob as ordens de seus empregadores, realizam o desmatamento desordenado de áreas florestais.

\section{REFERÊNCIAS}

BIRNIE, Patricia; BOYLE, Alan. International law and the environment. New York: Oxford University Press, 2009.

BRASIL. Decreto-lei n. 2.848, de 7 de dezembro de 1940. Código Penal. Disponível em: <http://www.planalto.gov.br/ccivil_03/decreto-lei/Del2848compilado.htm>. Acesso em: 21 set. 2018.

BRASIL. Constituição (1988). Constituição da República Federativa do Brasil. Disponível em: 〈http://www.planalto.gov.br/ccivil_03/constituicao/constituicaocompilado.htm〉. Acesso em: 21 set. 2018. 
COMISSÃO INTERAMERICANA DE DIREITOS HUMANOS. Convenção Americana de Direitos Humanos. (Assinada na Conferência Especializada Interamericana sobre Direitos Humanos, San José, Costa Rica, em 22 de novembro de 1969). Disponível em: $<$ https://www.cidh.oas.org/basicos/portugues/c.convencao_americana.htm>. Acesso em: 21 set. 2018.

CORTE INTERAMERICANA DE DERECHOS HUMANOS. Caso Trabajadores de la Hacienda Brasil Verde vs. Brasil Sentencia de 22 de agosto de 2017. Disponível em: $\langle$ http://www.corteidh.or.cr/docs/casos/articulos/seriec_337_esp.pdf $>$. Acesso em: 25 set. 2018.

DARCANCHY, Mara. (coord.). Direito, Inclusão e Responsabilidade Social. Estudos em homenagem a Carlos Aurélio Mota de Souza e Viviane Coêlho de Séllos Knoerr. São Paulo: LTr, 2013.

KNOERR, Viviane Coêlho de Séllos; DARCANCHY, Mara. Aids and ethics in the work environment: law and corporate citizenship in the protection of minorities. Revista Jurídica UNICURITIBA, V. 3, N. 44 (2016).

MAZZUOLI, Valerio de Oliveira. Teoria geral do controle de convencionalidade no direito brasileiro. In: BOGDANDY, Armin von; PIOVESAN, Flávia; ANTONIAZZI, Mariela Morales (Org.). Direitos humanos, democracia e integração jurídica: emergência de um novo direito público. Rio de Janeiro: Elsevier, 2013.

NOSCHANG, Patricia Grazziotin. O controle de convencionalidade na América Latina: influências do sistema interamericano de proteção aos direitos humanos. In: ROBL FILHO, Ilton Norberto; SCHELEDER, Adriana Fasolo Pilati (Org.).1. ed. Itajaí : Univali, 2016. v.1. p. 191-210.

O controle de convencionalidade na América Latina: influências do Sistema Interamericano de Proteção aos Direitos Humanos. In: OLIVO, Luis Carlos Cancellier de; BOTELHO, Alexandre; MOTA, Sergio Ricardo Ferreira (Org.). Direito e crítica. Homenagem ao Professor Antonio Carlos Wolkmer Estudos desenvolvidos no Programa de Pós Graduação em Direito da UFSC. Florianópolis: Insular, 2017. v.1. p. 255-272.

ORGANIZAÇÃO DAS NAÇÕES UNIDAS. Declaração do Rio sobre Meio Ambiente e Desenvolvimento. $1992 . \quad$ Disponível em: <http://www.onu.org.br/rio20/img/2012/01/rio92.pdf>. Acesso em: 25 set. 2018.

ORGANIZAÇÃO DAS NAÇÕES UNIDAS NO BRASIL. Agenda 2030. 2015. Disponível em: <https://nacoesunidas.org/pos2015/agenda2030/>. Acesso em: 21 set. 2018.

ORGANIZAÇÃO DAS NAÇÕES UNIDAS. Declaração do Rio sobre Meio Ambiente e Desenvolvimento. $1992 . \quad$ Disponível em: <http://www.onu.org.br/rio20/img/2012/01/rio92.pdf>. Acesso em: 25 set. 2018.

ORGANIZAÇÃO DAS NAÇÕES UNIDAS NO BRASIL. Agenda 2030. 2015. Disponível em: <https://nacoesunidas.org/pos2015/agenda2030/>. Acesso em: 21 set. 2018.

ORGANIZAÇÃO INTERNACIONAL DO TRABALHO. Conheça a OIT, [s.d]. Disponível em: <https://www.ilo.org/brasilia/conheca-a-oit/lang--pt/index.htm>. Acesso em: 20 set. 2018. 
ORGANIZAÇÃO INTERNACIONAL DO TRABALHO. O que é trabalho forçado, [s.d]. Disponível em: <https://www.ilo.org/brasilia/temas/trabalho-escravo/WCMS_393058/lang-pt/index.htm>. Acesso em: 20 set. 2018.

ORGANIZAÇÃO INTERNACIONAL DO TRABALHO. Agenda Nacional de Trabalho Decente. Disponível em: <https://www.ilo.org/wcmsp5/groups/public/---americas/---ro-lima/--ilo-brasilia/documents/publication/wcms_226229.pdf>. Acesso em: 20 set. 2018.

ORGANIZAÇÃO INTERNACIONAL DO TRABALHO. Normas Internacionais sobre Trabalho Forçado, 1930. Disponível em: <https://www.ilo.org/brasilia/temas/trabalhoescravo/WCMS_393063/lang--pt/index.htm.>. Acesso em: 25 set. 2018.

ORGANIZAÇÃO INTERNACIONAL DO TRABALHO. Constituição da OIT (1944) $e$ Declaração da Filadélfia (1946), [s.d.]. Disponível em: <https://www.ilo.org/wcmsp5/groups/public/---americas/---ro-lima/---ilobrasilia/documents/genericdocument/wcms_336957.pdf>. Acesso em: 26 set. 2018.

ORGANIZAÇÃO INTERNACIONAL DO TRABALHO. Declaração da OIT relativa a Princípios e Direitos Fundamentais no Trabalho, 1998. Disponível em: < https://www.ilo.org/public/english/standards/declaration/declaration_portuguese.pdf $>$. Acesso em: 26 set. 2018.

ORGANIZAÇÃO INTERNACIONAL DO TRABALHO, Documentos Fundamentais da OIT, $2007 . \quad$ Disponível em: $\langle$ https://www.ilo.org/public/portugue/region/eurpro/lisbon/pdf/constitucao.pdf $>$. Acesso em: 26 set. 2018.

ORGANIZAÇÃO INTERNACIONAL DO TRABALHO. Combatendo o trabalho escravo contemporâneo: o exemplo do Brasil. Brasília, 2010.

PIOVESAN, Flávia. Direitos humanos: desafios e perspectivas contemporâneas. Revista TST, Brasília, v. 75, n. 1, p. 107-113, 2009.

ROUSSEAU, Jean Jacques. Discurso sobre a origem e os fundamentos da desigualdade entre os homens, traduzido por Paulo Neves. Porto Alegre: L\&P, 2010.

SANDS, Philippe. Principles of International Environmental Law. 2. ed. Cambridge: Cambridge University Press, 2003.

SARLET, Ingo. Dignidade da pessoa humana e direitos fundamentais na Constituição Federal de 1988. Porto Alegre: Livraria do Advogado, 2001.

SCHRIJVER, Nico. Sovereignty over natural resources, Cambridge: Cambridge University Press, 1997.

SUSSEKIND. Arnaldo. Os direitos humanos do trabalhador. In: MENEZES DIREITO; Carlos Alberto; TRINDADE, Antonio Augusto Cançado; PEREIRA, Antônio Celso Alves. (Org.). Novas perspectivas do direito internacional contemporâneo - Estudos em homenagem ao Professor Celso D. de Albuquerque Mello. Rio de Janeiro: Renovar, 2008. p. 624-625. 
UNITED NATIONS. General Assembly. Declaração Universal dos Direitos do Humanos, $1948 . \quad$ Disponível em: <https://www. http://unesdoc.unesco.org/images/0013/001394/139423por.pdf>. Acesso em: 26 set. 2018.

ZIBETTI, Fabiola Wust; SOBRINHO, Liton Lanes Pilau; MIRANDA, Luiz Ricardo de. A INFLUÊNCIA DO CRITÉRIO DA SOBERANIA NAS FONTES DO DIREITO INTERNACIONAL. Revista Juridica, [S.1.], v. 3, n. 52, p. 106 - 128, jul. 2018. ISSN 2316$753 \mathrm{X}$. em: 23 abr. 2020. doi:http://dx.doi.org/10.21902/revistajur.2316-753X.v52i3.3050.

WINTER, Gerd. Desenvolvimento sustentável, OGM e responsabilidade civil na União Europeia. Campinas/SP: Millenium, 2009. 